Referencia para citar este artículo: Blanco, R., \& Vommaro, P. (2018). Activismo juvenil en los años ochenta en Argentina. Dos generaciones políticas entre el partido y la universidad. Revista Latinoamericana de Ciencias Sociales, Niñez y Juventud, 16(2), 839-852. doi:https://doi.org/10.11600/1692715x.16213

\title{
Activismo juvenil en los años ochenta en Argentina: dos generaciones políticas entre el partido y la universidad*
}

\author{
RAFAEL BLANCO ** \\ Profesor Universidad de Buenos Aires, Argentina. \\ PABLO VOMMARo *** \\ Profesor Universidad de Buenos Aires, Argentina.
}

\section{Artículo recibido el 3 de enero de 2018; artículo aceptado el 15 de febrero de 2018 (Eds.)}

- Resumen (descriptivo): este artículo analiza dos características principales del activismo juvenil que tuvo lugar en los partidos políticos y en la universidad pública en la década de 1980 en la Argentina. En primer lugar, indicamos como una particularidad del período la coexistencia de dos generaciones políticas en las organizaciones juveniles. En segundo lugar, señalamos la conformación de un emergente ethos ligado a la democracia como causa militante que estructura los lenguajes y repertorios de acción en ambos espacios. A partir de un trabajo de entrevistas en profundidad, se recupera aquí la dimensión cotidiana del activismo en un período de participación y movilización juvenil singular, en el que se produjeron cambios y rupturas respecto de la militancia de los años setenta.

Palabras clave: política, vida cotidiana, democracia, participación juvenil, organización juvenil (Tesauro de Ciencias Sociales de la Unesco).

\section{Youth activism in the 80s in Argentina: Two political generations between the party and the university}

- Abstract (descriptive): This article analyzes two main characteristics of youth activism that occurred in political parties and public universities in the 1980s in Argentina. Firstly, the authors highlight the coexistence of two political generations in youth organizations during this period. Secondly, the authors highlight the emergence of an ethos linked to democracy as a militant cause that structures the languages and repertoires of action in both spaces. From a set of in-depth interviews,

Este artículo de reflexión se basa en la investigación realizada por los autores en el marco de los proyectos del Programa UBACyT 20020130200085BA (2014-2017) dirigido por Melina Vázquez y co-dirigido por Pablo Vommaro y UBACyT 20020130300022BA (2014-2017) dirigido por Rafael Blanco, desarrollados entre el 30 de agosto de 2014 y el 31 de diciembre de 2017 y radicados en el Instituto de Investigaciones Gino Germani de la Universidad de Buenos Aires (IIGG-UBA). Área Ciencias Sociales, Sociología, Temas Especiales.

** Posdoctor en Ciencias Sociales, Humanidades y Artes por la Universidad Nacional de Córdoba, Doctor en Ciencias Sociales por la Universidad de Buenos Aires y Licenciado en Ciencias de la Comunicación (UBA). Investigador Conicet en el Instituto de Investigaciones Gino Germani (UBA). Integra el Grupo de Estudios de Políticas y Juventudes (Gepoju- IIGG) y el Programa de Estudios sobre la Universidad Pública (PesupIIGG). Es docente regular en la Facultad de Ciencias Sociales de la UBA. Orcid: 0000-0003-0730-6478. Índice H5:3. Correo electrónico: rafaelblanco@conicet.gov.ar

*** Posdoctor en Ciencias Sociales, Niñez y Juventud por el Cinde-Universidad de Manizales, Pucsp, Colef y Clacso. Doctor en Ciencias Sociales por la Universidad de Buenos Aires y Profesor de Historia (UBA). Investigador Conicet en el Instituto de Investigaciones Gino Germani (UBA). Integra el Grupo de Estudios de Políticas y Juventudes (Gepoju-IIGG) y el Grupo de Trabajo Clacso sobre Juventudes e Infancias. Es docente regular en la Facultad de Filosofía y Letras de la UBA. Orcid: 0000-0002-6957-0453. Índice H5: 12. Correo electrónico: pvommaro@gmail.com 
the study recovers the daily dimensions of activism in a period with high levels of youth participation and mobilization in which there are changes and ruptures following the militancy of the seventies.

Key words: Politics, daily life, democracy, youth participation, youth organization (Unesco Social Sciences Thesaurus).

\section{Ativismo Juvenil nos anos 80 na Argentina. Duas gerações políticas entre o partido e a universidade}

- Resumo (descritivo): $O$ artigo analisa duas características principais do ativismo juvenil na década de 1980 em Argentina que tiveram lugar nos partidos políticos e nas universidades públicas. Primeiro, a singularidade da coexistência de duas gerações políticas nas organizações de jovens. Em segundo lugar, observamos a formação de um ethos emergente ligado à democracia, que estrutura as causas militantes, as linguagens e os repertórios de ação em ambos espaços. A partir de entrevistas em profundidade, o artigo recupera aqui a dimensão cotidiana do ativismo, em um período de participação e mobilização da juventude singular, em que foram produzidas mudanças e rupturas com relação ao ativismo dos anos setenta.

Palavras-chave: política, vida cotidiano, democracia, participação juvenil, organização juvenil (Thesaurus de Ciências Sociais da Unesco).

-1. Presentación. -2. Dos generaciones políticas en las agrupaciones juveniles. -3. Las tensiones y articulaciones entre generaciones políticas. -4. Rasgos del emergente ethos militante. -5. Prácticas cotidianas entre el partido y la universidad. -6. Palabras finales. -Lista de referencias.

\section{Presentación}

Este artículo analiza un conjunto de lenguajes, causas militantes y repertorios de acción que tienen lugar en las agrupaciones juveniles en Argentina durante los años ochenta del siglo XX en dos escenarios: el partido y la universidad. Se propone recuperar la dimensión cotidiana de aquellas prácticas en el contexto de un período de participación y movilización juvenil singulares, en el que se produjeron cambios y rupturas tanto respecto a la militancia de los años setenta como así también respecto de los primeros años de la última dictadura cívico-militar (1976-1983). Como rasgos particulares, interesa marcar - por un lado - la coexistencia de dos generaciones políticas (Braungart \& Braungart, 1986, 1989; Longa, 2017; Mannheim, 1993) y en las organizaciones juveniles; por el otro, la emergencia de un ethos militante ligado a los nuevos sentidos que adquiere la democracia, la vida partidaria y la masificación del espacio universitario en el período posdictatorial. Ambos rasgos modulan la participación juvenil en los dos ámbitos en los que este texto se detiene.

A partir de un trabajo de entrevistas realizadas entre marzo y noviembre de 2015 a diez cuadros medios o dirigenciales de las juventudes de distintos espacios políticos y líneas internas (Juventud Intransigente, Federación Juvenil Comunista, Juventud Radical, Juventud Peronista, Partido Socialista de los Trabajadores), de expresiones estudiantiles secundarias y universitarias (Franja Morada, Frente Intransigente Secundarios, Juventud Universitaria Intransigente) o que participaron en experiencias organizacionales juveniles transversales como el Movimiento de Juventudes Políticas (Mojupo), nos proponemos reconstruir algunos rasgos particulares de las prácticas y los espacios cotidianos de militancia — más que las dinámicas de la estructura organizativa - en la década señalada. Para ello, nos basamos en testimonios producidos a partir de entrevistas en profundidad que siguieron la metodología de la historia oral. Esto implica la construcción de fuentes orales a partir de testimonios de diferentes participantes de los procesos y espacios de militancia estudiados. Resaltamos el carácter dialógico de la entrevista y las múltiples dimensiones que hay que considerar al trabajar con el testimonio oral que fueron incluidas en el análisis (Jelín, 2001; Joutard, 1986; Necoechea \& Pozzi, 2008; Portelli, 1997). Si bien este artículo puede permitir pensar otras prácticas situadas, por 
diferencias o similitudes, nuestro foco estará puesto en narrativas de actores que han participado políticamente en la Ciudad Autónoma de Buenos Aires.

A partir del análisis realizado podemos hipotetizar, en primer lugar, que una de las transformaciones más significativas que se producen en los años ochenta es el pasaje de una experiencia de militancia juvenil heterogénea, marcada por la simultaneidad de dos generaciones políticas, hacia una creciente profesionalización del activismo, en el sentido de una mayor diferenciación y especialización militante, sobre el final de la década. En segundo lugar, que algunos rasgos que aparecen aquí como significativos van a marcar las tensiones respecto de las formas de participación de las juventudes en democracia más allá del período aquí trabajado, tales como la centralidad de la democracia en tanto significante que estructura las prácticas y causas militantes o la creciente especialización de la militancia según ámbitos de desempeño.

El artículo se organiza en cinco secciones seguidas de unas palabras finales. Luego de esta introducción, en segundo lugar, nos interesa centrarnos en los inicios de la década como un momento de coexistencia de distintas tradiciones militantes en las juventudes políticas. En tercer término, focalizamos en el proceso de reconversión política de aquellos que venían de la experiencia de los años setenta y en las formas de transmisión que van a articular a ambas generaciones políticas. En cuarto lugar, analizamos los principales rasgos de lo que caracterizamos como la emergencia de un ethos epocal del activismo juvenil vinculado con la «promesa de la democracia». En la quinta sección nos centramos en el modo en que este ethos configura prácticas militantes, tales como la participación en la vida partidaria o en el cogobierno de las universidades públicas. Las palabras finales retoman algunos hallazgos y sugieren posibles indagaciones futuras.

\section{Dos generaciones políticas en las agrupaciones juveniles}

Un rasgo que atraviesa las prácticas militantes y configura los espacios políticos de este período es la coexistencia de dos generaciones políticas en las organizaciones juveniles durante lo que llamamos tempranos ochentas. Con esta denominación nombramos el momento de creciente politización que se produjo en los primeros años de la década, signado en gran medida por los acontecimientos en torno a la Guerra de Malvinas (1982) que constituyó un hito epocal.

Como analizan Aboy-Carlés (2001) y Pereyra (2013), anteriormente habían comenzado a producirse acontecimientos y movilizaciones políticas ya no exclusivamente por parte de los organismos de derechos humanos, sino también impulsados desde sindicatos (con la convocatoria al paro general en 1979) y partidos políticos (que conformaron la Multipartidaria en 1981). Pero la derrota bélica de 1982 da lugar a una aceleración del proceso de apertura política que se expresó también en las militancias juveniles.

En cuanto a la coexistencia de dos generaciones políticas, nos referimos a la convivencia en los ámbitos de politización que aquí estudiamos de jóvenes que experimentaron su socialización, habitaron sus espacios de sociabilidad, construyeron lazos y se subjetivaron como militantes tanto en los años setenta (antes o durante la última dictadura), junto a quienes lo hicieron en los tempranos ochentas o ya en la democracia. Entre las personas entrevistadas con experiencias de militancia anteriores a los años ochenta podemos señalar como común denominador el inicio de su participación política entre los catorce y diecisiete años de edad, en los centros de estudiantes secundarios y, en algunos casos, durante los primeros años de la universidad. La pertenencia a grupos como la Unión de Estudiantes Secundarios (UES, de orientación peronista), la militancia barrial, la participación en reuniones y asambleas en sindicatos o en manifestaciones en el espacio público, constituyen algunos de los espacios de participación inscriptos en distintas corrientes y tradiciones políticas de la izquierda, el peronismo y el radicalismo. Conforme avanzan los años setenta, las experiencias de detención por parte de las fuerzas de seguridad (tanto en la débil democracia entre 1974 y 1976, como ya en la dictadura), la cárcel, la desaparición de amigos y militantes cercanos y el exilio (en Brasil, México, Francia o España), marcan las biografías de quienes tendrán participación política en la década 
siguiente. Esta generación de jóvenes militantes, veinteañeros en los tempranos ochentas, articula en sus trayectorias políticas dos temporalidades: la experiencia de los años setenta y su inscripción en un escenario distinto, en el que la democracia — más que la revolución, como también apunta Ollier (2009) - emerge como significante constitutivo de las causas y repertorios de acción política.

En cambio, otras personas entrevistadas se incorporan por primera vez a organizaciones estudiantiles y juveniles en los años ochenta, en espacios en algunos casos preexistentes como la Franja Morada, la Juventud Intransigente (JI) o la Federación Juvenil Comunista (FJC), que movilizan las adhesiones de quienes no habían tenido experiencia militante previa. Sin embargo, las simpatías, tradiciones o identificaciones partidarias se habían forjado en un estado deliberativo anterior, especialmente en las discusiones familiares. Por ello, aún cuando para estos jóvenes los inicios de su militancia daten de los años ochenta, en las entrevistas identificamos que esta se inscribe en experiencias políticas familiares previas que marcan un primer momento en el propio activismo. Con el inicio del último golpe militar, la conversación familiar en el espacio resguardado del hogar fue uno de los géneros, de los formatos disponibles, en los que persistió activamente la discursividad política. Como recuerda un ex militante de la Juventud Radical Renovación y Cambio: «cuando fue el golpe en el 76 nosotros teníamos prohibido hablar en la calle, pero en mi casa se hablaba» ${ }^{1}$. A su vez, la vida en la clandestinidad, los cambios de nombres para proteger identidades, las agendas telefónicas y calendarios suprimidos, las identificaciones y referencias personales duplicadas, la detención, el secuestro, el exilio o la desaparición de un familiar van a constituir huellas en las biografías de las y los entrevistados que marcarán también el posterior devenir político. A partir de estos hallazgos interesa enfatizar que el comienzo de la militancia juvenil en los años ochenta está precedido, en muchos casos, por una formación política que se conformó en el ámbito doméstico, familiar.

Entre quienes habían militado en los años setenta y quienes se incorporan a la política en los inicios de los años ochenta existen tensiones respecto de los modos de articulación del pasado reciente con aquel presente. «Los pibes que entran en la militancia, la mayoría, una gran parte, entra después de Malvinas», recuerda una entrevistada del por entonces Partido Socialista de los Trabajadores (PST) que retornó del exilio en el año 1982, a donde partió luego de haber estado detenida durante la última dictadura. Y agrega: «y esa camada es una camada muy interesante porque quiere saciarse de experiencias de los setentas. Está abierta. Siente admiración por la militancia de los setentas». En otros relatos, el lazo con los años setenta no se traduce en admiración ni, mucho menos, en imitación al modelo de la militancia juvenil anterior.

Un rasgo que ubicamos como significativo en nuestro análisis entre quienes comienzan a militar en los tempranos ochentas, es que lo hacen a partir de un proceso de relativa desidentificación con las generaciones anteriores. Si los procesos de identificación involucran, al decir de Stuart Hall (2003), los usos de los recursos de la historia, la cultura y la lengua en la conformación de un devenir, la generación de los ochenta traza una relación distanciada con las causas y repertorios de acción propios del ciclo histórico anterior. Un entrevistado - que fue referente universitario de la JI- refiere haber elegido «no militar a los 16 años en los restos del partido en donde había militado mi papá y en dónde habían secuestrado a dos integrantes de la dirección», para luego tomar distancia no solo de ese espacio sino también de la izquierda marxista: «ya más a los 18 años decidí no militar en la izquierda clásica a pesar de que todo me acercaba a ellos por ese lado».

Tal vez uno de los puntos centrales que articulan las diferencias entre las dos generaciones políticas sea el lugar que ocupa en cada una la creencia en la democracia como «un valor en sí mismo». Esta valoración fue central en la retórica de Raúl Alfonsín, el presidente electo en 1983 (Aboy-Carlés, 2001; Pereyra, 2008). Si la apelación a la democracia en los años setenta carecía de sentido por la sucesión de dictaduras y proscripciones políticas que signaron a la Argentina luego de 1955, en los años ochenta será uno de los puntos de encuentro más valorados entre jóvenes de ambas generaciones

1 En lo sucesivo, aquellas expresiones entrecomilladas refieren a voces textuales de las entrevistas. En algunos casos en los que las citas son más extensas, se diferencian con otra tabulación para facilitar su lectura. 
políticas. Para la mayoría de las y los militantes entrevistados con experiencia en años anteriores esto significará no solo una desidentificación con su propia trayectoria, sino un verdadero proceso de aculturación: prácticas, lenguajes, repertorios de acción diferentes a los de una primera subjetivación política van a configurar el escenario de las formas emergentes de la política en el período.

Así, quienes habían tenido experiencias de militancia en los setentas tenían el recuerdo vívido, tal vez en parte por la falta de una experiencia prolongada en la vida democrática, de las connotaciones negativas que la idea de «democracia» tenían en su primer lenguaje político. Un «cierto desprecio», «casi como hasta como un escollo», entre otras significaciones mencionadas, parecen estar sintetizadas en un canto popular que un entrevistado rememora de un acto de la JP en la cancha del equipo de fútbol Nueva Chicago en 1972 al que concurrió con su familia: «ni votos, ni botas, fusiles y pelotas». No obstante, esta primera socialización política (Kriger \& Dukuen, 2017; Winneburg, 2001), sobre el final de la década de 1970 y comenzando los años ochenta, la realidad cotidiana vivida en el marco del Estado terrorista, con sus consecuencias de represión y muerte, junto con otros procesos como la revisión crítica de la militancia armada y las experiencias formativas del exilio, renuevan los sentidos de la democracia. Este significante llegó a constituirse - aún antes de las elecciones de 1983 - «en la única idea para hablar de la política: ordenó todas las discusiones político-ideológicas de una época» (Reano \& Smola, 2014, p. 34). Entonces, tanto la causa de los derechos humanos, agenda dominada — no sin polémicas y divisiones - por los reclamos por la aparición con vida de las personas desaparecidas y el binomio «verdad y justicia», como la búsqueda de estrategias para «llegar» a la democracia se transforman en orientaciones predominantes que trazaran puntos en común entre prácticas militantes de diferentes tradiciones.

\section{Las tensiones y articulaciones entre generaciones políticas}

Siguiendo a Merklen (2005), podemos decir que desde los tempranos ochentas se construye un consenso a partir del cual se definen los contornos de lo que sería considerado «buena política», cuyo actor principal es el ciudadano, el acto político por excelencia es la participación en elecciones a través del voto y la representación política debía articularse por vía de los partidos políticos. Una consigna que recuerda un entrevistado que participó activamente del Mojupo representando a la JI, sintetiza la inscripción revalorizada de la democracia en una nueva trama política: «nuestro compromiso con el pueblo, nuestro camino la democracia, nuestro destino la liberación».

Para quienes tenían una trayectoria militante de más larga data, la creencia en que la democracia constituía «un valor en sí mismo» implicó un acercamiento a una realidad política muy distinta a la que habían tenido en los inicios de su activismo. Un referente de la Juventud Peronista recuerda que, con 24 años, «para muchos jóvenes yo era como una especie de veterano» que asistía, sin embargo, a un nuevo comenzar político que combinaba tanto la perspectiva de la recuperación democrática como así también la resignificación de prácticas anteriores: «para mí era la continuidad de la lucha, lo tenía muy claro», en sus palabras.

Así, quienes provenían de experiencias de militancia anteriores reconvierten su trayectoria en los años ochenta, en un proceso que una referente de la Juventud Peronista de entonces va a definir como «el pasaje de la militancia a la política». Con este cambio de sustantivos el testimonio muestra la transformación de los repertorios de acción e imaginarios que configuran lo político de una década a la otra. «Para nosotros política no era una palabra muy usada, nosotros éramos militantes», refiere acerca de las formas de autoidentificación en los años setenta. Esto marca la diferencia con la década siguiente en la que «la política era discutir quién iba al parlamento, quiénes eran concejales». Este relato refuerza la idea de que la buena política, retomando a Merklen (2005), por entonces comenzaba a ligarse a las instituciones republicanas como forma legitimada de militar en la democracia.

Sin cancelar las distancias y lo que denominamos como un proceso de desidentificación, recuperamos en el análisis múltiples formas de transmisión entre una generación política y la otra. Por 
caso, visitar a presos políticos en las cárceles de Buenos Aires, experiencia que retoma un entrevistado de la JI, posibilita una conversación entre generaciones que produce y acompaña la reelaboración que se realiza de la experiencia militante de los setenta. Asimismo, los espacios de formación de los partidos también constituyen un ámbito de transmisión intergeneracional. La historia de los diferentes partidos políticos, la situación nacional e internacional, las formas de organización interna (que el radicalismo, recuerda un entrevistado de una línea minoritaria, cultivaba como parte de su institucionalidad en tanto marca identitaria) son parte de la formación. Un referente de la Juventud Radical recuerda el sistema de formación de su partido, que sobre el final de la dictadura se reorganizaba para disputar el gobierno: «nosotros teníamos cuadernillos de formación, de discusión, el n. ${ }^{\circ} 1$, el n. ${ }^{\circ} 2$. No te digo que tomábamos examen, pero...»

Estudiar, formarse, «poder hablar bien», «poder escribir» y el «énfasis en que había que comunicar bien lo que se hacía» eran algunas de las habilidades que un entonces miembro de la Fede ${ }^{2}$ recuerda como aprendizajes relevantes de su formación política en el partido, junto con las brigadas solidarias que partieron a distintos países de América Latina ya avanzada la década. Las tareas de transmisión son asumidas explícitamente por algunos militantes como parte de los esfuerzos de formación política de las nuevas generaciones. «La gente que veníamos de los setentas teníamos una misión política y cultural», recuerda una militante trotskista que había participado de las escuelas de formación política de su partido en aquella época, «porque había que traer la experiencia de los setentas que se había cortado en la dictadura». Por su parte, en el PI leer, estudiar y debatir textos de Antonio Gramsci, Arturo Jauretche o Raúl Scalabrini Ortiz forma parte de las actividades periódicas de reflexión política, con el objeto tanto de retomar tradiciones de la izquierda como de conformar — en palabras de un dirigente universitario de entonces - una variante «nacional, popular y democrática».

Estas instancias de elaboración colectiva participan de la definición del significado que asume la democracia en los primeros años ochenta: la distancia con la lucha armada y la radicalización política, la insurrección o la confrontación militar, el reclamo de elecciones libres y la legalización de la participación política en partidos. La gestación de estos sentidos compartidos posibilita la articulación de identidades políticas diferentes, con tradiciones disímiles, en agrupaciones radicales, peronistas, comunistas o intransigentes que, siendo distintas, se unían en un mismo reclamo. Un referente de la FJC que participó de las reuniones iniciales del Mojupo recuerda que estas se organizaban en distintos colegios públicos de la ciudad de Buenos Aires (el Nacional Buenos Aires, el Instituto Libre de Segunda Enseñanza, el Huergo, el Otto Krause, o el Reconquista, entre otros) pero también en locales partidarios, más allá de las diferencias políticas. «Había mucha comunión de las fuerzas políticas, vos pensá que realmente sentíamos y pasaba que estábamos fundando la democracia», recuerda el entrevistado para destacar luego el carácter iniciático de aquella experiencia común que trascendía las diferencias previas: «teníamos unas broncas tremendas y disputas, pero nos sentíamos parte de que estábamos fundando algo, que estaba pasando y que era nuevo».

Esta posibilidad de articulación de diferentes espacios políticos y experiencias generacionales a partir de la identificación con la democracia como valor político durante los últimos años de la dictadura es una de las condiciones de posibilidad que permitieron la articulación del Mojupo, movimiento que se extendió hasta pasado el primer lustro de la década. Así, la defensa de la democracia, que requirió múltiples movilizaciones durante el gobierno constitucional que se inició en 1983, encontrará a las juventudes políticas articuladas en torno a esta causa.

Hasta acá, destacamos que los primeros años de la década de 1980 están marcados por varios elementos. Por un lado, un clima micropolítico de recomposición de las formas de organización, participación y formación. Por el otro, la reactivación de espacios de militancia juvenil que se asientan tanto sobre tradiciones políticas y familiares anteriores, como así también sobre la reelaboración de experiencias previas, lenguajes y formas de apropiación del pasado reciente a partir de lo que aparece como lo novedoso: la valorización la democracia como causa movilizadora de las prácticas cotidianas.

2 Denominación coloquial que recibía la Federación Juvenil Comunista, brazo juvenil del Partido Comunista Argentino. 
ACTIVISMO JUVENIL EN LOS AÑOS OCHENTA EN ARGENTINA:

DOS GENERACIONES POLÍTICAS ENTRE EL PARTIDO Y LA UNIVERSIDAD

\section{Rasgos del emergente ethos militante}

Otro rasgo a destacar en las militancias juveniles de los años ochenta es la emergencia de un ethos militante que deviene punto de confluencia entre estas. Referimos a ethos en el sentido en que lo ha sistematizado Montero (2012) a partir de diferentes articulaciones sociológicas, discursivas y filosóficas, como concepto que permite dar cuenta de las formas en las que se articulan creencias, valores e ideologías con el terreno de la práctica y la acción política, en coordenadas espaciotemporales específicas.

A comienzos de la década el crecimiento y mayor visibilidad de la participación política tiene impacto no solo en la presencia pública de las organizaciones y la presentación de sus causas y demandas, sino también en las prácticas cotidianas, las creencias, los lenguajes y, grosso modo, en el entramado cultural que dota de sentido al activismo. En parte, el lema de campaña del radicalismo, «Somos la vida, somos la paz», ubica un rasgo de ese nuevo clima de época: la oposición respecto a la dictadura militar anterior, la «frontera con el pasado» (Aboy-Carlés, 2001, p. 168) a partir de la que construye su legitimidad el gobierno entrante. De un modo más general, indica el distanciamiento de lo que se consideraba como cultura política propia de los años anteriores, signada por la violencia y el procesamiento armado de los conflictos. La democracia es asumida como «un valor en sí», como característica del emergente ethos militante. Esto se expresa en las luchas por la búsqueda de juicio y castigo a los responsables del genocidio perpetrado por la dictadura, en el reclamo de aparición con vida de los desaparecidos y en las acciones que buscan el restablecimiento de las libertades individuales.

En las prácticas cotidianas esta valorización de la democracia como delimitación de la buena política se traduce en la asunción de «una responsabilidad», como consignan diversos relatos. Esta era el trabajo en las instituciones: en el partido, en los poderes del Estado, en el cogobierno universitario, en los centros de estudiantes. Así, la importancia del trabajo en las instituciones como signo característico de los nuevos sentidos de la militancia es concomitante con la crítica a la lucha armada, que procedía de diversos espacios.

Como dijimos, algunos de quienes militan en agrupaciones juveniles habían vivido la experiencia del exilio. «La distancia y el vivir en otros países te hace repensar muchas cosas», retoma una entrevistada que militó en los años setenta y continuó luego en la Juventud Peronista a su retorno del exilio en la España del posfranquismo y en México. El regreso al país de aquellos que se habían ido con apenas veinte años propicia en algunos casos una relectura de la experiencia anterior a la luz del nuevo escenario para que se pudieran «repetir los aciertos y no reproducir los errores», según el testimonio de un militante que, tras una participación breve en la UES en los setenta, milita en la Juventud Intransigente ya durante la democracia. Estos testimonios también coinciden con el análisis realizado por Ollier (2009) para quien la experiencia transformadora del exilio reconfiguró las subjetividades de quienes regresaban al país.

Este emergente ethos se conforma en el contacto con un nuevo clima de época: nuevos materiales, revisiones y un renovado espectro cultural con el que el activismo juvenil tomaba contacto. En las entrevistas, las referencias a las lecturas de revistas que se enmarcaban en proyectos intelectuales de envergadura (como Controversia, Contorno, Crisis, Punto de Vista y posteriormente Ciudad Futura) colaboran en la revisión de las orientaciones que guiaban la militancia de los años setenta. Esto se expresa también en otras publicaciones, destinadas a un público más amplio (como El Periodista, Humor o El Porteño), que marcan las transformaciones de la vida cotidiana, las costumbres y los lenguajes producidos en esa época.

Estas revistas operan también como un espacio de transmisión entre generaciones. Por un lado, académicos, académicas e intelectuales que retornan del exilio, o bien que retoman con fuerza la palabra pública, polémica, luego del exilio interno y revisan la experiencia propia y generacional de los años setenta en proyectos editoriales que devenían en otra forma de compromiso político. Por el 
otro, una nueva generación de lectores que elabora su experiencia militante en aquel presente de la mano de lecturas que circulan entre los referentes del activismo juvenil entrevistados. Uno de ellos recuerda los debates que se producían en el exilio argentino en México, que Controversia plasma, y que contribuyen a su formación política: «me abrió mucho la cabeza digamos, me desobligó de pensar en la revolución marxista-leninista». Se trataba, así, de elaboraciones que propiciaban — como sostienen Reano y Smola (2014) — una reapropiación teórica y política del concepto de democracia, sin abandonar la idea de «transformación» propia del pensamiento de izquierda, pero amalgamado a la valoración de la «participación»: «el desafío consistía en recuperar la relación entre "lo político" y "lo público" como forma de reconstrucción del espacio de "lo común”» (Reano \& Smola, 2014, p.114). En este sentido, consideramos estimulantes las contribuciones de Cosse (2016), quien estudia los modos en los que ciertas publicaciones o revistas emblemáticas producen marcas generacionales e inciden en la configuración de tensiones que pueden conmocionar a la sociedad y producir la emergencia de contradicciones o representaciones desestabilizantes en términos generacionales, sociales y culturales (Cosse, 2016, pp. 1550-1551).

Así, el ethos militante gestado al calor del entramado de dos generaciones se encarna, a su vez, en la renovación de formas expresivas de lo político, que se articulan en búsquedas creativas y celebratorias por el fin de la dictadura. Las peñas, los recitales de rock, las fiestas en locales partidarios, son también escenarios de militancia para los y las jóvenes que, con distintas intensidades, participan de las transformaciones que revitalizan el espacio político y público en los primeros años de la década. «En el local nuestro, de la juventud, hacíamos peña de centenares de maestras, cosa que hoy no soy capaz de juntar y lo digo con toda sinceridad», recuerda una militante trostkista del entonces PST; y agrega: «hacíamos esfuerzos increíbles de decoración de los locales: para una fiesta lo habíamos decorado como una piscina, porque el local era celeste. Entonces habíamos puesto peces y ahí colgamos peces del techo». El clima festivo, celebratorio, lúdico, y la alegría por la rehabilitación de las posibilidades de reunión, no eran solo medios para cumplir objetivos propiamente políticos. Tenían una finalidad en sí misma como parte del proceso de politización juvenil de la época. La entrevistada mencionada continúa: «una fiesta en ese momento significaba mucho: había mucha alegría porque era la posdictadura, y tenía la posibilidad de expresarse más socialmente. Siempre terminábamos con fiesta».

La juventud comunista, por su parte, se caracteriza por lo que un ex militante refiere como «la cosa cultural»: el festival «Arte y parte» que se realizaba anualmente en el barrio porteño de Palermo, o la «Ferifiesta» en el Parque Sarmiento. Este rasgo distintivo demuestra la capacidad de este espacio político de movilizar artistas populares de la época, que fueron identificados con el Partido Comunista como Mercedes Sosa, Víctor Heredia, el Cuarteto Zupay o León Gieco. Mientras que estos artistas convocan a grandes multitudes atraídas por la celebración cultural con dimensión política en un movimiento que también contribuyó a la articulación entre generaciones, la cultura propiamente juvenil de la época parece ir adquiriendo otros referentes: Sumo, Soda Stereo, Los Twist, Los Abuelos de la Nada, Zas, Virus o Charly García, por entonces flamante solista. Tal como lo señaló tempranamente Vila (1989), el revitalizado movimiento del rock nacional de los años ochenta puede ser concebido como un espacio político que contribuye a la visibilización de los y las jóvenes como sujetos legitimados en el espacio público, pero que parece encontrar algunas resistencias por parte de una parte del activismo juvenil para ser apropiado plenamente en su dimensión política. Si este vínculo en los ochenta aparece tenue, en algún grado y sin desconocer las mediaciones específicas (Semán, 2016), los procesos de politización juveniles en la década siguiente tendrán como una de sus marcas la identificación con el rock (Isacovich, 2014), en particular como modo de contestación ante la agudización de procesos represivos en democracia, especialmente aquellos vinculados con la violencia policial e institucional. 
ACTIVISMO JUVENIL EN LOS AÑOS OCHENTA EN ARGENTINA:

DOS GENERACIONES POLÍTICAS ENTRE EL PARTIDO Y LA UNIVERSIDAD

\section{Prácticas cotidianas entre el partido y la universidad}

La referida emergencia de un ethos político en los años ochenta también posibilita la renovación de ciertas prácticas de activismo en espacios tradicionales. Nos referimos a la forma-partido (Negri, 1999) que adquiere la militancia y a la delimitación de la especificidad del activismo militante en la universidad. La afiliación a los partidos políticos se configura como una de las maneras predominantes de asumir el compromiso de la participación política en el que el valor simbólico de adscribirse formalmente a un partido excede la dimensión burocrática de esta adhesión. Un miembro de la FJC recuerda que un tercio de sus compañeros de aula se afiliaron a la Fede: «muchos no tenían la más puta idea de El manifiesto comunista, ni les importaba; era bueno, "llegó la democracia y puedo ser comunista, o puedo ser radical o puedo ser del PI"».

Como parte de las denominadas buenas prácticas de la naciente democracia, el proceso de afiliación constituye un signo deseado de bautismo político. El valor positivo que para unos tenía el completar fichas de ingreso al partido contrasta con el significado asignado a esta actividad por quienes tenían una trayectoria militante en los setenta, que veían en estas tareas partidarias de la militancia un signo de burocratización y hasta de despolitización. Un entrevistado describe como "partidocrático» el clima político que encontró luego de su retorno del exilio. Así, afirma que «nosotros no sabíamos qué era eso, la ficha de afiliación a los partidos, los punteros políticos, yo nunca había vivido eso, cuando llegué acá me impresionó porque todo el mundo se estaba afiliando». Vemos entonces cómo este tipo de tareas que comienzan a ocupar buena parte del tiempo de la militancia juvenil implican habitar lo que podemos denominar la vida de partido, que para muchos constituye una experiencia inédita.

Por otra parte, en la universidad comienzan a producirse formas específicas de intervención política que implican una mayor atención a las especificidades de la vida en las casas de estudio, a sus lógicas, demandas singulares y a la experiencia estudiantil como esfera de politización (Blanco, 2014; Blanco, 2016a; Picotto \& Vommaro, 2010). Esto se debe en parte a la rápida mutación de las universidades públicas luego de la última dictadura pero también a la llegada de nuevos estudiantes y el crecimiento de la matrícula. Los planes de estudio, los cuerpos docentes, las formas de organización y la agenda nacional, pero también los apuntes y fotocopias o las condiciones edilicias se tornan parte de demandas y causas militantes en un escenario universitario masificado. Nos centramos ahora en este punto para aproximarnos a la experiencia del activismo en el espacio universitario, con el objeto de trascender la mera descripción institucional (Perrupato, 2017).

En efecto, la universidad se transforma en un espacio singular de militancia que cobra importancia en parte debido a la rápida masificación que experimentó, en gran parte por la modificación de las políticas de ingreso que eliminaron barreras y permitieron la llegada de nuevos estudiantes. Sin embargo, es importante considerar el señalamiento de Buchbinder y Marquina (2008), quienes sostienen que si bien el ingreso se hizo irrestricto desde 1983, al año siguiente las universidades comenzaron distintas formas de restricciones y mecanismos de selección y nivelación de los estudiantes que aspiraban a ingresar en la vida universitaria. Las cifras del crecimiento de la matrícula son elocuentes: «en 1983 había 416 mil estudiantes universitarios en la Argentina, en 1984 llegaron a casi 500 mil. En 1986 superaban los 700 mil» (Buchbinder \& Marquina, 2008, p. 28). Este aumento se dio principalmente en el sistema universitario público, mientras que - siguiendo a estos autores - en el privado la matrícula se redujo en un 9\% entre 1983 y 1986. En el caso de la UBA, «el número de estudiantes pasó de un poco más de 100 mil en 1982 a casi 162 mil en 1987» (2008, p. 29), junto con la implementación del Ciclo Básico Común (CBC) como forma de restricción del ingreso, en el año 1985.

El crecimiento de la matrícula universitaria es acompañado con algunas transformaciones institucionales, entre las que aquí resaltaremos las sucedidas en las humanidades y ciencias sociales. En la UBA se fundan nuevas facultades (como Ciencias Sociales, Psicología), carreras (Ciencia Política, Comunicación, Relaciones del Trabajo, las carreras de diseño) y numerosos posgrados. También se visibilizan nuevas disciplinas y campos de conocimiento como los estudios de género, los estudios 
culturales, el auge del posestructuralismo, las traducciones de Gramsci y el impacto de Foucault (Blanco, 2016b). Estas transformaciones movilizan nuevos debates en las aulas ya que en parte expresan la incorporación a la universidad de grupos y espacios de discusión y activismo creados por fuera de la institución en los últimos años de la dictadura y los primeros de la democracia. El regreso de docentes exiliados, cesanteados o autoexiliados durante la dictadura, sumado al crecimiento de la matrícula estudiantil y a los espacios intelectuales y políticos que emergieron, configuran un clima universitario que creció en cantidad y en heterogeneidad. Esto impacta en las formas de militancia situadas y constituye uno de los cambios sucedidos en los escenarios de militancia durante los años ochenta que va a aportar a la conformación del ethos militante.

La Juventud de Partido Intransigente (JI) y la Juventud Universitaria Intransigente (JUI) son dos de las agrupaciones que mejor parecieron capturar ese nuevo clima de época, a la vez que fueron una expresión de este. Por ello, cuando sobreviene el desencanto político hacia el final de la década, también mermó su capacidad para contener al nuevo estudiantado. Podemos decir que la JI y la JUI encarnaban cierto ideal regulatorio de la militancia de los ochenta ya que se trataba de espacios legitimados que, en la mirada de un entrevistado radical, amalgamaban las dosis de compromiso y especificidad que van a adquirir la experiencia política estudiantil en la universidad. «Lo más divertido era ser el PI, era más como lo que había que ser», expresó en la entrevista.

Este lugar destacado que tienen estos espacios entre la militancia universitaria de los años ochenta puede explicarse también en que, a la vez que representan a un número creciente de jóvenes, no «cargan con el peso» de ser el brazo juvenil o universitario del partido oficialista (como en el caso de Franja Morada). Es decir, se encuentran a una relativa distancia de un gobierno que conforme avanza la década comienza a enfrentar diversos cuestionamientos y a perder respaldo popular. En efecto, en los cinco años comprendidos entre 1982 (cuando ganó dos centros de estudiantes de la UBA y peleó las elecciones en otros) y 1987, la Juventud Intransigente supo atraer a las nuevas generaciones de militantes y organizar gran parte de la actividad política en las universidades disputando espacios con la Franja Morada, principal fuerza universitaria por entonces.

Asimismo, distintas expresiones de la juventud radical canalizan por entonces las experiencias militantes fuera y dentro de la universidad. No se trataba de espacios monolíticos sino de la coexistencia de líneas internas, con pugnas, tradiciones distintas y diferentes posicionamientos ante determinadas medidas del Poder Ejecutivo y ante el liderazgo de Alfonsín. Esto tensa sus dinámicas y lleva a fragmentaciones y al distanciamiento de buena parte de su militancia hacia el final de la década. Su núcleo más visible en aquellos años, la Junta Coordinadora Nacional (conocida simplemente como «la Coordinadora»), según el análisis que en la época realizó Carlos Altamirano, posibilita «un proceso de renovación generacional de cuadro militantes que dotó a la UCR de nuevos recursos políticos y organizativos, así como amplió su inserción en el tejido social, sobre todo en el campo de los movimientos juveniles» (1987, p. 328). Recuerda un ex militante de la Corriente Nacional y Popular, enfrentada con el oficialismo de la JR: «El discurso de la Coordinadora era la eficiencia, la libertad, "somos la vida, somos la paz", nunca haber hecho una alianza con el peronismo, nosotros sí».

Las juventudes radicales representan al partido de gobierno y, si bien disputan con la JI los votos en el escenario universitario, al mismo tiempo mantienen con esta una estrecha convivencia institucional debido a la participación en el cogobierno universitario y en la Federación Universitaria de Buenos Aires (Fuba, espacio gremial estudiantil). Con otras organizaciones como la Juventud Universitaria Peronista (JUP) o con los grupos juveniles y universitarios de la organización trostkista Movimiento al Socialismo (MAS) las relaciones eran, en cambio, más tensas y los diálogos menos fluidos.

El ethos militante referido configura las prácticas en la universidad. Si la democracia era asimilada como «un valor en sí», el cuidado de la institucionalidad implicaba una responsabilidad y el debate, como forma democrática de disenso, una herramienta para fortalecerla. Por ello, el trabajo en el cogobierno universitario constituye un aprendizaje político que involucra entender el funcionamiento 
institucional de las facultades ya no solo atendiendo a las formas de desarticular la herencia de cursos, programas y docentes que habían sedimentado desde la última dictadura, sino también en las tareas que demandaba la planificación de una dinámica institucional democrática y plural. El trabajo en los órganos de cogobierno de la universidad implicó también el vínculo con nuevos actores: las diversas agrupaciones con representación política, las decisiones del gobierno y el Ministerio de Educación, las asociaciones y colegios profesionales, las y los investigadores y docentes que volvían del exilio o bien habían trabajado por fuera de la vida universitaria durante el período dictatorial, los trabajadores administrativos, entre otros sectores.

Asimismo, surgen por entonces otros actores como las agrupaciones autodenominadas «independientes» que, en el recuerdo de un dirigente de la JR, eran las que «te decían que a la universidad no se iba a hacer política, que se iba a mejorar la calidad de la educación universitaria y de la vida del estudiante». Esta vertiente de grupos estudiantiles que se identifican como independientes, no vinculados a estructuras partidarias, inaugura un derrotero de la política estudiantil universitaria que reivindica la independencia, o bien de los partidos políticos en general, o bien de los partidos en el gobierno (como lo fue el caso de la Upau, ligada a la centro derechista UCeDé) ${ }^{3}$. La autodenominación «independiente»se irá transformando entre los años ochenta y los noventa, y va a ir adquiriendo distintos significados según los momentos históricos y sus conflictos (Blanco, 2016a; Cortés \& Kandel, 2002; Picotto \& Vommaro, 2010). En los años ochenta estos grupos parecen concentrarse —en un vocabulario actual- más en la gestión que en el gobierno. «Más cursadas, mejores apuntes, más tóner en las fotocopiadores, pero independiente del proyecto nacional» recuerda otro dirigente juvenil radical de entonces.

En el renovado espacio universitario la contienda electoral implica mucho más que el sufragio. Durante los primeros años de la recuperación democrática se producen aprendizajes políticos en cuestiones como el desarrollo de plataformas, su discusión pública y las campañas electorales. Como señala Toer (1988), luego de la regularización de las federaciones estudiantiles a fines de 1983, con una participación encuadrada en identidades político partidarias, la militancia del movimiento estudiantil universitario estuvo enfocada ya no tanto en «los grandes acontecimientos de la vida nacional» sino en el cogobierno universitario, trabajo sobre el que la mayoría de las agrupaciones no tenía una sostenida experiencia previa, habida cuenta de las sucesivas intervenciones de las que habían sido objeto las universidades públicas. Esto requirió la elaboración de estrategias y la producción de prácticas hasta entonces poco transitadas.

En este proceso de aprendizaje militante basado en los requerimientos que iban surgiendo en el trabajo político cotidiano, la atención a las realidades de las facultades, las carreras y las materias, constituye una parte fundamental de la tarea política. Un ex militante del PI que cursó en los años ochenta la carrera de Sociología recuerda que revisar la bibliografía que había sido prohibida durante la dictadura, pergeñar la reforma de los planes de estudios y pensar las articulaciones entre la universidad y la recuperada democracia eran parte de la tarea militante. "Los compañeros de las agrupaciones de ciencias de la salud, odontología, farmacia, medicina, habían agarrado la plataforma del PI del 73 y habían hecho una reelaboración del Sistema Nacional Integrado de Salud» recuerda el entrevistado, «entonces iban a las elecciones del centro de estudiantes postulando que había que terminar con las obras sociales, que había que unificar todo un sistema de medicina socializada al estilo británico».

A modo de cierre de este apartado, podemos decir que el activismo estudiantil en la universidad construye su especificidad en una difícil tensión entre la singularidad de una institución encargada de la transmisión de conocimiento y su inscripción en la vida política, social y cultural que la modula. Si nos interesa señalar aquí esta cualidad que adquirió el activismo juvenil en los años ochenta es porque progresivamente, y con algunas excepciones como las de las agrupaciones independientes de fines de los años noventa y comienzos de los dos mil (Picotto \& Vommaro, 2010), este rasgo se irá perdiendo

3 Unión de Centro Democrática, fundada por Álvaro Alsogaray. Su rama universitaria, la Unión para la Apertura Universitaria (Upau) se formó en 1983 y tuvo su pico de crecimiento en el año 1987. 
en los años posteriores desplazada por cierta sobredeterminación de las agendas externas y las lógicas partidarias, como señalan Carli (2012) y Blanco (2014, 2016a), en un fenómeno que Pedro Krotsch denominó como «debilitamiento de una cultura específicamente universitaria» (2014, p. 162) de las agrupaciones estudiantiles, algo que ya comenzará a insinuarse sobre el final de la década estudiada.

\section{Palabras finales}

Nos interesó aquí aportar a la reconstrucción de algunos rasgos particulares de las experiencias de militancia juvenil a nivel cotidiano en dos escenarios particulares, el partido y la universidad. Hemos hecho hincapié especialmente en la relación entre generación y juventud (Vommaro, 2015) con el objeto de identificar algunas transformaciones de su presencia en la escena pública (Feixa, 2011), en un período especial de la participación política en Argentina: la recuperación democrática en los años ochenta. Remarcamos dos procesos que se gestan en este período: la coexistencia de dos generaciones políticas (quienes provenían de las experiencias de los años setenta y quienes se politizan en las organizaciones juveniles en los años ochenta) y la conformación de un nuevo ethos que establece puntos en común entre ambas.

Este ethos se articula en torno a la democracia como significante estructurador de las prácticas y los repertorios de acción. Los procesos de transmisión entre generaciones políticas, como así también la revisión del pasado reciente que se realiza entonces, colaboran en la configuración de los rasgos políticos que serán una de las marcas generacionales de la época estudiada. Vale decir que esa revisión de los años setenta, de proximidad y distancia con esa época, va a continuar en un movimiento incesante entre las agrupaciones juveniles hasta nuestros días (Núñez, 2011; Vázquez, Vommaro, Núñez \& Blanco, 2017). Por entonces, esta revisión se expresa en un emergente lenguaje de derechos (Pereyra, 2013) que se tradujo en acciones militantes cotidianas: el trabajo en el partido, las responsabilidades institucionales del cogobierno universitario, la conformación de espacios juveniles transversales a diferentes agrupaciones, entre otros. A su vez, este ethos se correspondió con escenarios de participación estructurados por nuevas reglas y dinámicas, entre las que en este artículo enfocamos en el partido y la universidad. Esto va a suponer una creciente especialización y diferenciación de formas y espacios de militancia que se distinguen a partir de sus singularidades delimitadas a lo largo de la década.

Como último elemento que aquí solo insinuamos y nos proponemos desarrollar en futuros trabajos, es interesante identificar el proceso por el cual el ethos militante que se configura en los años ochenta comienza a mostrar signos de agotamiento sobre el final de la década y va a dar lugar al surgimiento de otras formas de compromiso, que van a delimitarse con mayor claridad en la década siguiente, como el activismo juvenil territorial (Vommaro \& Vázquez, 2008), la «reflexividad estética» (Molinari, 2011) o una heterogeneidad de procesos de repolitización que se producen al calor de la resistencia al neoliberalismo (Kriger \& Said, 2017). Esta búsqueda política en clave generacional no se realizará ya con la sombra de la última dictadura como límite y la militancia de los años setenta como opuesto, sino desde los aprendizajes de la experiencia de esos años que mostraron el agotamiento de la militancia centrada en la democracia como causa pública y los espacios institucionales como ámbitos predominantes de realización política juvenil.

\section{Lista de referencias}

Aboy-Carlés, G. (2001). Las dos fronteras de la democracia argentina: la reformulación de las identidades politicas de Alfonsin a Menem. Buenos Aires: Homo Sapiens.

Altamirano, C. (1987). La Coordinadora: elementos para una interpretación. En J. Nun, \& J. C. Portantiero (Comps.), Ensayos sobre la transición democrática en la Argentina, (295-332). Buenos Aires: Puntosur. 
Blanco, R. (2014). Estudiantes, militantes, activistas: nuevas agendas de las agrupaciones universitarias en torno al género y la diversidad sexual. Perfiles Educativos, XXXVI. doi:https://doi.org/10.1016/ S0185-2698(14)70628-2

Blanco, R. (2016a). Escenas militantes: lenguajes, identidades politicas y nuevas agendas del activismo estudiantil universitario. Buenos Aires: Grupo Editor Universitario, Clacso. Recuperado de: http://biblioteca.clacso.edu.ar/clacso/gt/20171218053503/Escenas_militantes.pdf

Blanco, R. (2016b). Trayectorias académicas en los estudios sobre géneros y sexualidades: tensiones entre profesionalización, activismo y experiencia biográfica. Educação e Pesquisa, 42(3), 727740. doi:http://dx.doi.org/10.1590/S1517-9702201609153533

Braungart, R., \& Braungart, M. (1986). Life-course and generational politics. Annual Review of Sociology, 12, 205-231.

Braungart, R., \& Braungart, M. (1989). Youth status and national development: A global assessment in the 1980s. Journal of Youth and Adolescence, 18, 107-130. doi:10.1007/BF02138796.

Buchbinder, P. \& Marquina, M. (2008). Masividad, heterogeneidad y fragmentación: el sistema universitario argentino 1983-2007. Buenos Aires: UNGS, Biblioteca Nacional.

Carli, S. (2012). El estudiante universitario: hacia una historia del presente de la educación pública. Buenos Aires: Siglo XXI.

Cortés, C., \& Kandel, V. (2002). Reflexiones en torno a las nuevas formas de participación estudiantil en la vida política de la universidad. Fundamentos en Humanidades, 3(5), 23-34.

Cosse, I. (2016). «Ese monstruito»: Mafalda, generaciones y género en una construcción mítica. Revista Latinoamericana de Ciencias Sociales, Niñez y Juventud, 14(2), 1549-1561. doi:10.116 00/1692715x.14245210915

Feixa, C. (2011). Generación XX. Teorías sobre la juventud en la era contemporánea. Revista Latinoamericana de Ciencias Sociales, Niñez y Juventud, 4(2), 21-46.

Hall, S. (2003). Introducción: ¿quién necesita identidad? En S. Hall, \& P. du Gay (Comps.), Cuestiones de identidad cultural, (pp. 13-39). Buenos Aires: Amorrortu.

Isacovich, P. (2014). La juventud como lenguaje político: reflexiones a partir de un incendio en un recital de rock. Sociedade e Cultura 2014, 17(1), 97-107. doi:https://doi.org/10.5216/sec. v17i1.36881

Jelín, E. (2001). Exclusión, memorias y luchas políticas. En D. Mato (Comp.), Estudios Latinoamericanos sobre cultura y transformaciones sociales en tiempos de globalización (pp. 91-110). Clacso: Buenos Aires.

Joutard, Ph. (1986). Esas voces que nos llegan del pasado. México, D. F.: FCE.

Kriger, M., \& Dukuen, J. (2017). Haciendo de la necesidad virtud: socialización política y herencia familiar entre becarias de un colegio de clases altas (Caba). Revista Pilquen, 20(3), 67-81.

Kriger, M., \& Said, Sh. (2017). Hacer política desde la escuela: narrativas biográficas de jóvenes en Argentina. Revista Latinoamericana de Ciencias Sociales, Niñez y Juventud, 15(2), 1085-1096, ago. doi:10.11600/1692715x.1521920122016

Krotsch, P. (2014). Los universitarios como actores de reformas en América latina: ¿han muerto los movimientos estudiantiles? En S. Carli (Dir. y Comp.), Universidad pública y experiencia estudiantil: historia, política y vida cotidiana (pp. 141-165). Buenos Aires: Miño y Dávila.

Longa, F. (2017), ¿Existen las generaciones políticas? Reflexiones en torno a una controversia conceptual. Íconos. Revista de Ciencias Sociales, 58, 205-222. doi:https://doi.org/10.17141/ iconos.58.2017.2051

Mannheim, K. (1993). El problema de las generaciones. Revista Española de Investigaciones Sociológicas, 62, 193-244.

Merklen, D. (2005). Pobres ciudadanos: las clases populares en la era democrática. Buenos Aires: Gorla.

Molinari, S. V. (2011). Juventudes argentinas, una forma de mirar al mundo: entre la voluntad de los '70 y la reflexividad estética de los '90. Revista Latinoamericana de Ciencias Sociales, Niñez y Juventud, 4(1), 61-82. 
Montero, A. S. (2012). Los usos del ethos: abordajes discursivos, sociológicos y políticos. Revista de Retórica, 2, 223-242.

Necoechea, G., \& Pozzi, P. (2008). Cuéntame cómo fue: introducción a la historia oral. Buenos Aires: Imago Mundi.

Negri, A. (1999). Las verdades nómadas \& General Intellect, poder constituyente, comunismo. Madrid: Akal.

Núñez, P. F. (2011). La redefinición del vínculo juventud política en la Argentina: un estudio a partir de las representaciones y prácticas políticas juveniles en la escuela secundaria y media. Revista Latinoamericana de Ciencias Sociales, Niñez y Juventud, 6(1), 149-190.

Ollier, M. M. (2009). De la revolución a la democracia: cambios privados, públicos y políticos de la izquierda argentina. Buenos Aires: Siglo XXI.

Pereyra, S. (2008). ¿La lucha es una sola? La movilización social entre la democratización y el neoliberalismo. Buenos Aires: UNGS.

Pereyra, S. (2013). Procesos de movilización y movimientos sociales desde la transición a la democracia. Revista Observatorio Latinoamericano, (32), 235-253.

Perrupato, S. (2017). Pensar la historia de las instituciones educativas en la Argentina: aportes para el debate. Revista Latinoamericana de Ciencias Sociales, Niñez y Juventud, 15 (2), 797-806. doi:1 $0.11600 / 1692715 x .1520102082016$

Picotto, D., \& Vommaro, P. (2010). Jóvenes y política: una incursión por las agrupaciones de estudiantes independientes de la Universidad de Buenos Aires. Revista Nómadas, (32), 149-162.

Portelli, A. (1997). The battle of Valle Giulia: Oral history and the art of dialogue. Madison: The University of Wisconsin Press.

Reano, A., \& Smola, J. (2014). Palabras políticas: debates sobre la democracia en la Argentina de los ochenta. Buenos Aires: Ediciones Universidad Nacional de General Sarmiento (UNGS), Universidad Nacional de Avellaneda (Undav).

Semán, P. (2016). Música, juventud, hegemonía: salidas de la adolescencia. Estudios Sociológicos, 34(100), 3-40. Recuperado de:

http://www.scielo.org.mx/scielo.php?script=sci_arttext\&pid=S2448-64422016000100003\&lng $=\mathrm{es} \& \mathrm{t} \operatorname{lng}=\mathrm{es}$.

Toer, M. (1988). El movimiento estudiantil de Perón a Alfonsín. Buenos Aires: Ceal.

Vázquez, M., Vommaro, P., Núñez, P., \& Blanco, R. (2017) Introducción: pensar las militancias juveniles desde los años recientes. En P. Vommaro, M. Vázquez, P. Núñez, \& R. Blanco (Comp.), Militancias juveniles en la Argentina democrática: trayectorias, espacios y figuras de activismo. Buenos Aires: Imago Mundi.

Vila, P. (1989). Rock nacional, crónicas de la resistencia juvenil. En E. Jelin (Comp.), Los nuevos movimientos sociales. Buenos Aires: Ceal.

Vommaro, P. (2015). Juventudes y políticas en la Argentina y en América Latina: tendencias, conflictos y desafios. Buenos Aires: Grupo Editor Universitario, Clacso. Recuperado de: http://biblioteca. clacso.edu.ar/clacso/gt/20160905042410/Juventud-y-Politicas.pdf

Vommaro, P., \& Vázquez, M. (2008). La participación juvenil en los movimientos sociales autónomos de la Argentina: el caso de los Movimientos de Trabajadores Desocupados (MTDs). Revista Latinoamericana de Ciencias Sociales, Niñez y Juventud, 6(2), 485-522.

Winneburg, S. (2001). Historical thinking and other unnatural acts. Philadelphia: Temple University Press. 